\title{
USING MICROWORLDS FOR RESILIENCE MANAGEMENT OF FOOD SYSTEMS
}

\section{Dr Hugo Herrera}

University of Bergen, Department of Geography, System Dynamics Group

Fosswinckelsgt. 65020 Bergen

hugojhdl@gmail.com

\section{Dr Birgit Kopainsky}

University of Bergen, Department of Geography, System Dynamics Group

Fosswinckelsgt. 65020 Bergen

birgit.kopainsky@uib.no

\begin{abstract}
Resilience management of food systems requires building understanding of the underlying drivers of systems adaptive capacity. We argue that system dynamics models and simulations can be used to inform discussions aiming to such resilience by providing interactive environments to experiment with different policies. We make this argument based on our experience analysing the key structures conditioning the response of beef farming systems in France to climate change effects. The analysis illustrate how small and aggregated system dynamics models can foster understanding about mechanisms driving resilience by facilitating discussions about its drivers, opportunities for intervention and their trade-offs.
\end{abstract}

Keywords: System dynamics, Microworlds, Resilience, Food Systems

\section{INTRODUCTION}

Food systems are socio-ecological systems (SES) in which a variety of stakeholders interact through a wide range of activities such as production, packaging, selling and consumption of food (Ericksen, 2008). The objectives for food systems include long-term sustainability of food security and social and environmental outcomes (Ericksen, 2008). A prerequisite for long-term sustainability is the capacity of a system to maintain its functionality without compromising its ability to do so in the future. There is an increased awareness of the vulnerabilities of food systems to changes in the environment like those introduced by climate change (e.g. water scarcity, weather variability) (Campbell et al, 2016; Tendall et al, 2015). This is particularly the case in Europe, where food systems are experiencing changes in the technological, demographic, environmental and economic landscape (Knickel et al, 2016, Saifi and Drake, 2008).

Socio-ecological resilience is essentially understood as a system ability to maintain its functionality even when it is being affected by a disturbance (Folke et al, 2010; Holling, 1996). While sustainability provides a framework for long-term planning, resilience focuses on adaptive mechanisms that will support a system functionality in the medium and long-term future. The emphasis on adaptive mechanisms to unpredictable changes has made resilience a compelling forward-looking approach to adaptation (Pizzo, 2015) attracting the attention of researchers and policymakers.

While resilience is a characteristic of the system, resilience management is the active modification of a system with the explicit aim to improve its capacity to absorb and adapt to change (Nettier et al, 2017; Fath et al, 2015; Walker et al, 2002). These capacities depend on the way the system has been organised and, therefore, resilience management is interested in understanding such organisation and identifying more effective ways for structuring the system.

According to Walker et al (2002: 14), the aims of resilience management are a) to prevent a system from transitioning into undesirable configurations in the face of external shocks and $b$ ) to cultivate the conditions that facilitate system adaptability following a massive change. Undesirable 


\section{Herrera and Kopainsky}

configurations can be operationalised as the set of conditions and relations within the system that prevent it from providing its main outcomes. For instance, in the case of food systems, undesirable configurations are those that prevent them from providing: enough, affordable and good quality food; sustainable revenues for farmers; or enough jobs in their communities.

The second aim proposed by Walker et al (2002: 14) suggests that a resilience management process is not a normative process, but a structured and systematic framework that allows stakeholders to adapt to challenges in the environment (Nettier et al, 2017; Holling \& Gunderson, 2002). In this paper we work towards this aim by focusing on means to analyse and communicate the mechanisms driving resilience of food systems (Sieber et al, 2018; Biesbroek, et al., 2014).

Namely, we illustrate how small models can inform our understanding of the system structure and the mechanisms driving the system responses to external shocks. Next, we present the analysis and insights gained from using a small system dynamics model to explore resilience of food systems in France. The paper proceeds as follows, first, we start by describing what are microworlds for resilience management. Next, we briefly describe the case study, the model that was prepared for its analysis and a summary of the results the model produced. The paper concludes with and a short discussion describing the kind o benefits that can be gained from using small models for resilience management.

\section{MICROWORLDS FOR RESILIENCE MANAGEMENT}

Building resilience through resilience management requires to understand social, economic and environmental aspects of food systems (De Bruijn et al, 2014; Berkes, 2009). With this purpose, systems should be studied as a whole and the processes and subsystems within the system viewed as interdependent (Bruijn et al, 2017; Walker et al, 2002). Elements of the system traditionally considered in isolation are often part of complex structures linking them and conditioning the system outcomes (Spielman et al., 2009).

The complexity of food systems arises from the large number of interactions between many actors (e.g. farmers, retailers, workers, local governments, national governments, etc.) (Schut et al, 2014) and food systems interdependencies with socio-technical and socio-ecological systems (Giller et al, 2008; Schut et al, 2014; Olsson et al, 2014). This complex network of interactions and interdependences introduces time delays between causes and effects, reducing decidability and making it difficult for decision-makers to anticipate systems responses to shocks and changes (Davidson, 2010; Axelrod and Cohen, 2000).

One alternative for dealing with such complex systems is to use analytical constructs that help decisionmakers and stakeholders to make sense of the real world and operationalise resilience concept. Morecroft (1992) introduced the concept of 'microworlds for policymaking debate'. Microworlds are system dynamics (SD) models that act as transitional objects stakeholders can use to explore scenarios, experiment and debate. This 'microworlds' help to foster understanding among stakeholders by capturing stakeholders knowledge into diagrams and enriching that knowledge with the insights from computer simulations (Morecroft, 1992).

SD models are helpful constructs for enhancing understanding about resilience because they aggregate detail while focusing on dynamic complexity, focusing on the main relationships between aggregated parts of the system and how these interactions evolve over time makes it easy to identify points for intervention. Having a simulation model also offers an opportunity for exploring the system response to different disturbance. While resilience overall is a wide, and vague, concept (Herrera, 2017; Tendall et al, 2015), it can be operationalised through the system outcomes and their behaviour when affected by an externa disturbance (Bruijn et al, 2017; Walker et al, 2004). Whereas each outcome is likely to exhibit its own particular response, for simplicity, these responses can be cluster in three big groups:

a) building robustness: creating the overall conditions that allow the system to withstand the shocks from the environment without significant changes in its outcomes' behaviour. Building robustness often requires building infrastructure or building capabilities providing a first response to extreme weather conditions (e.g. creating food banks).

b) increasing stakeholders adapting capacity: fostering stakeholders' ability for managing the system and respond to changes in the environment. These strategies often focus on making 


\section{Herrera and Kopainsky}

critical thresholds and tipping points more difficult to reach by making the access and distribution of key resources more flexible across different sectors within the system (Walker et al, 2004). For instance, decentralised governance, stakeholders' networks and opportunities for innovation are often seen as critical strategies for adaptation (Biggs et al, 2012).

c) preparing for managing transformation: preparing for massive changes that otherwise could results on effects at large and catastrophic scales. If the system transforms to create a new fundamental new system, stakeholders' might be deprived of fundamental services provided by the previous system. Preparing for transformation requires to explore cross-scale interactions with other systems for building redundancy.

SD models are also great tools for identifying 'control' ('slow') variables (Ludwig et al, 1978; Holling, 1986; Carpenter and Turner, 2000). Control variables, often described as slow because they need time to change (be depleted or accumulated), differentiate from other variables because they shape how other variables, particularly outcomes, respond to external drivers. For example, soil organic matter is a control variable because, as described by Walker et al (2012), it shapes how crop production responds to variations in rainfall (external driver) during growing season.

By focusing on how control variables change it is possible to understand why systems respond differently to shocks from external variables (changes in the environment). Shocks to the system introduce might have an impact on control variables but won't produce significant change in the outcomes if the resources remain within certain thresholds. As the shocks increase in magnitude or frequency, control variables move closer to the threshold and fluctuations in the outcomes became more pronounced. These fluctuations are the results of the internal dynamics of the system and the action of feedback loops within the system (Walker et al, 2012; Carpenter and Brock, 2008; Scheffer et al, 2009). Once key resources reach their thresholds, the strength of these feedback loops shifts and the system moves towards a different, and potentially undesired, configuration exhibiting different behaviours.

In the reminded of the paper we illustrate how a small SD model can be used to facilitate policymaking debate on resilience of beef farming systems in France. The model is an aggregated conceptual system dynamics model built using historical data, case studies described in the literature (e.g. Lien et al, 2007 study in Norway and Eakin and Wehbe, 2009 studies in Latin America) and insights from the research conducted in the SURE-Farm project. SURE-Farm is a research and innovation project funded by the European Union's Horizon 2020 programme and involves 16 universities and research institutes from 11 European countries. Its full title is "Towards SUstainable and REsilient EU FARMing systems".

While the model structure is generic to many livestock and mixed crops-livestock systems, in this paper we focused on beef cattle systems in France. Having a simplified model is advantageous in this case because allow us to expand on the explanation of the analysis performed rather than spend long time describing the model itself.

\section{A MICROWORLD FOR MANAGING RESILIENCE OF BEEF FARMING SYSTEMS}

Farming is one of France's most important industries. The country is self-sufficient in food supplies, from cereal crops, to beef, pork and poultry to fruit and vegetables. Beef production is of economic importance since meat production is the biggest agri-food business in the country (Eurostat, 2016).

Figure 1 portrays the basic structure of the beef farming system. This structure is a simplified diagram compared to the actual system dynamics model. In Figure 1 the 'livestock units (LU)' stock represents the total amount of cattle held by the farmers in the region. The amount of livestock units is depleted by the 'slaughtering LU' outflow and replenished and increased by the 'Replacement and additional LU' inflow. The revenues from beef production are used to paid dividends to the shareholders of the farm whom, if the return on their equity is higher than the return offered in the market, decide the replenish and increase the LU (R1-Profits driving growth on livestock in Figure 2). 


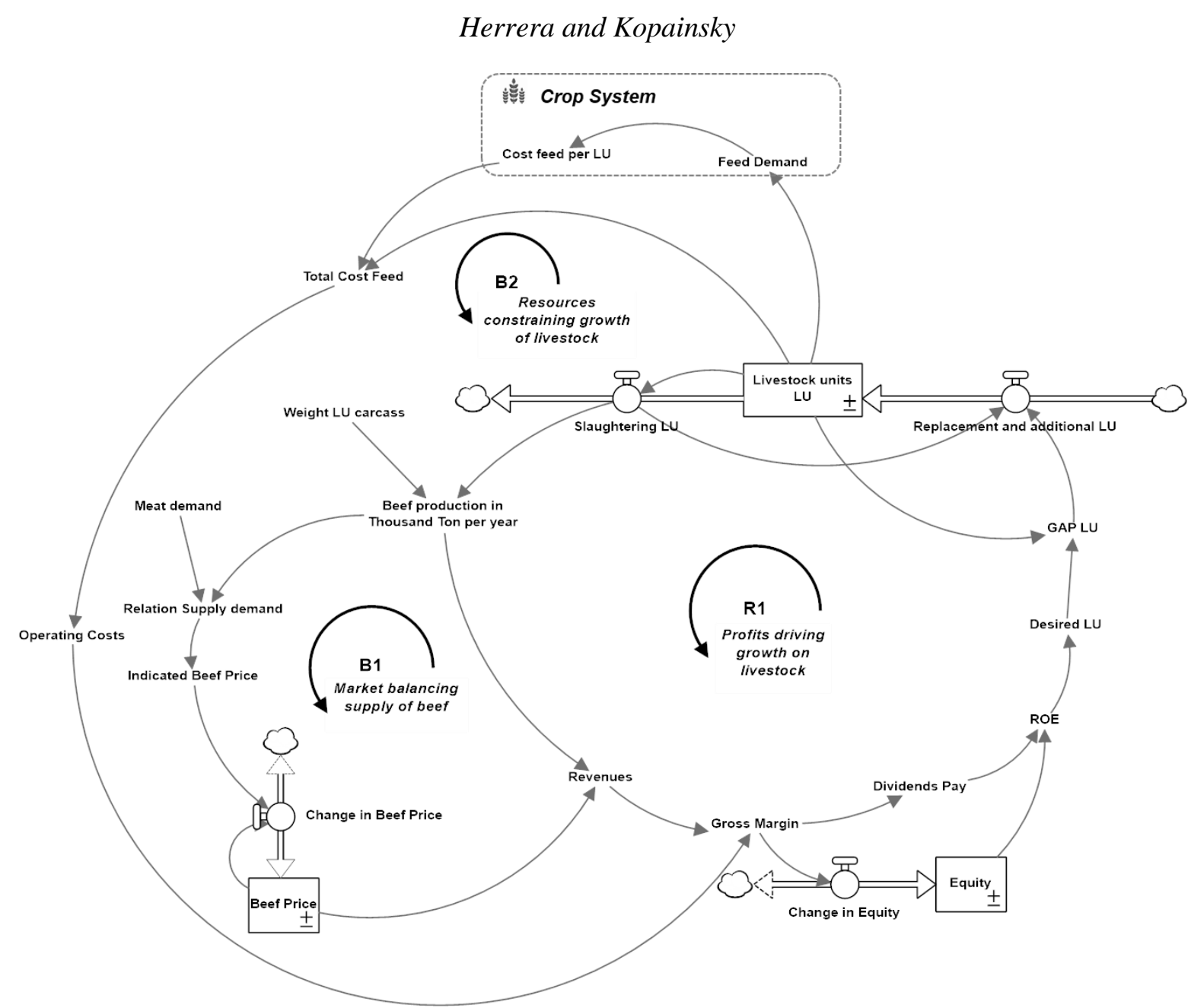

Figure 1 Illustrative structure beef farming system

The 'Replacement and additional LU' also depends on the selling price for the meat. The meat selling price is assumed to be elastic to the relation between supply and demand. Hence, the size of the beef farming system is constrained by the rate at which the markets (local and international) change (see B1 Market balancing supply of beef in Figure 1). Similarly, the size of the beef farming system is constrained by the resources available for production (e.g. land, feed, and workforce). In the diagram this constrained is represented by the cost of acquiring such resources with the costs increasing as they become scarcer (see B2 Resources constraining growth of livestock in Figure 1).

\subsection{Introducing the impact of climate change}

The change in weather patterns is a visible global phenomena (IPCC, 2013). There is substantial evidence showing that climate conditions are quickly changing around the globe as result of a sustained increase in the global mean temperature (Wheeler and von Braun, 2013). Food systems are intrinsically sensitive to changes in the weather and highly vulnerable to climate change (Campbell et al, 2016; Ericksen, 2008).

Climate change is likely to have a direct effect on the environmental drivers in ways that will diminish food system capability to support food production. For instance, the increase of droughts and weather variability is expected to result in a net reduction in crop yields (Schmidhuber and Tubiello, 2007; Wheeler and von Braun, 2013). In livestock systems, the effects of climate change are both direct and indirect. Directly, the increase in mean temperatures resulting from climate change will have an impact on the animals themselves. Indirectly, the climate change effects on production of crops and grasslands will increase operating costs making it difficult for animals to gain weight (Silanikove and Koluman, 2015).

To introduce these indirect effects, additional structure is needed in the model. Figure 2 portrays the basic structure of a crop system producing animal feed as well as crops for human consumption. 


\section{Herrera and Kopainsky}

As before, the structure shown in Figure 2 is a simplified diagram compared to the actual model, but illustrates the main dynamics analysed.

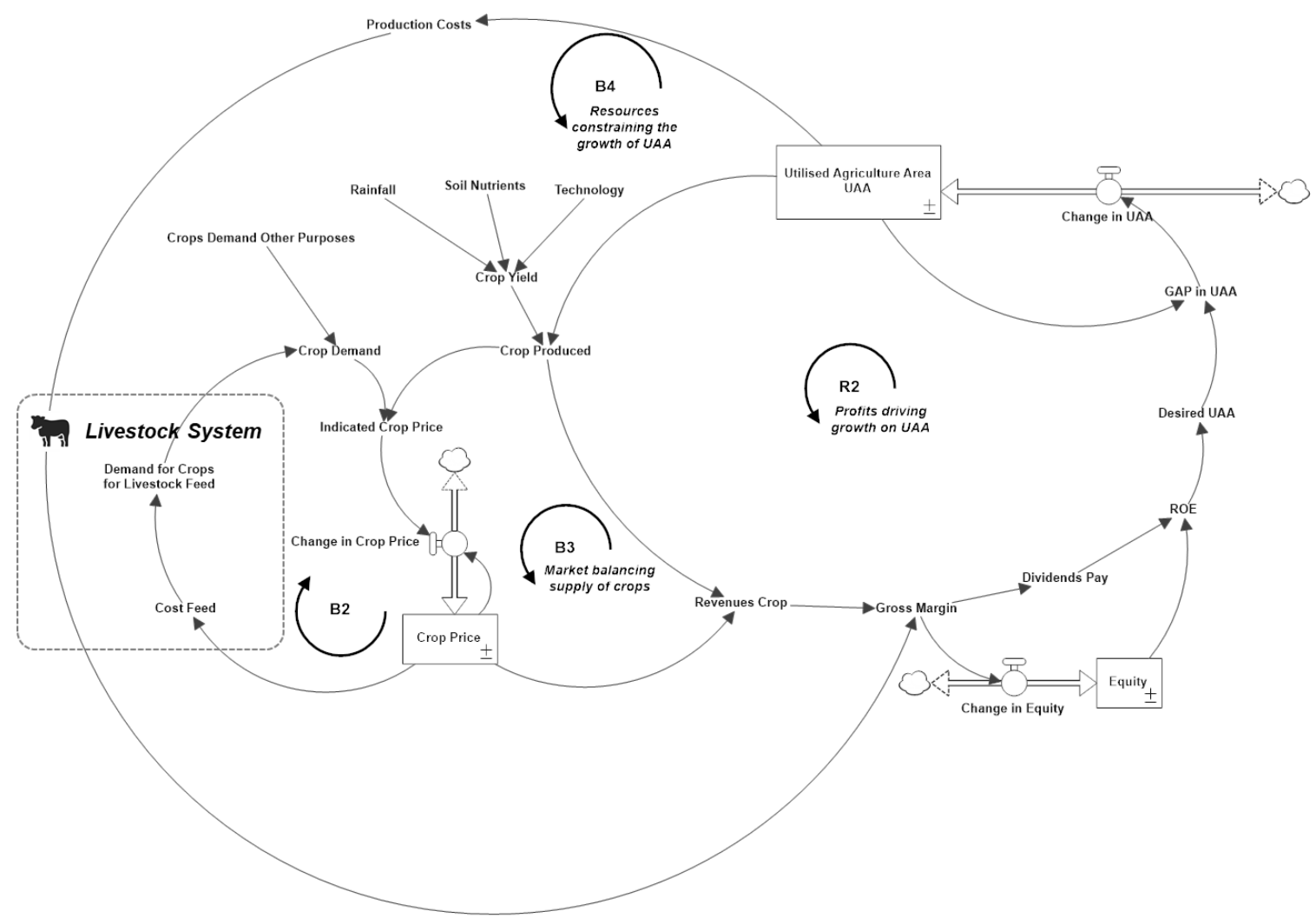

Figure 2 Illustrative structure crop production system

The amount of crop produced depends on the amount of utilised agricultural area (UAA) and the average yield per UAA. Like in the case of beef production, highest crop production results on higher revenues and incentive investment on more UAA and more and larger farms (see R2-Profits driving growth on UAA in Figure 2). Like in the beef farming, the investment on UAA is constrained by the demand (see B3-Market balancing supply of crops in Figure 2) and the resources available (see B4Resources constraining the growth of UAA in Figure 2). As the UAA increases, the quality of the land used is likely to be less suitable for crop production due to deficiencies in soil nutrients, landscape and water access. However, the model assumes these deficiencies could be resolved by spending more on fertilisers, irrigation and other operating costs and we opted for keeping yields constant while making operational costs proportional to the UAA.

\section{ANALYSIS AND RESULTS}

The outputs of the model operationalise farming systems' performance through the outcomes and functions they provide to the region. For our analysis we used a selection of indicators suggested by the SURE-Farm resilience framework (Meuwissen et al, 2019). In particular, we looked at the system capacity to: i) deliver healthy and affordable food products and ii) ensure its economic viability. In this case, we used the proxy variables 'beef production' and 'price per carcass' as approximations of those outcomes. Using the model, we analysed the resilience of the French beef cattle systems to climate change by simulating the behaviour of those variables under more challenging weather conditions. Many studies regarding the potential impact of climate change in agriculture show that changes in weather conditions and increase on pests could reduce crops yields in Europe. For analysis purposes, we considered the system response to a single shock in weather conditions that will temporarily reduce crops' yield for a three years period. The simulation results for these variables are presented in Figure 3. 


\section{Herrera and Kopainsky}

Reaction to a moderate shock

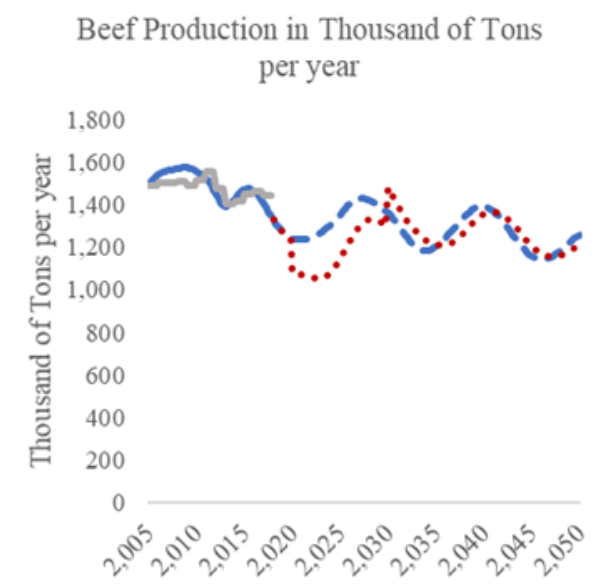

Reaction to an extreme shock

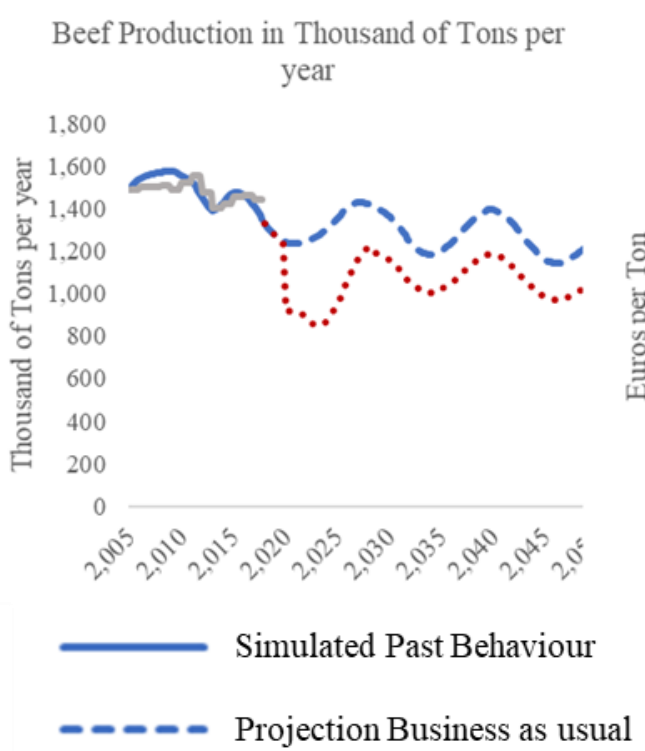

Beef Production in Thousand of Tons per year

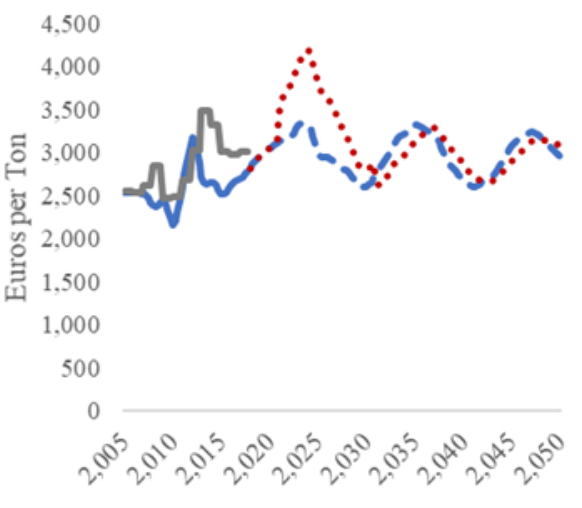

Beef Production in Thousand of Tons per year

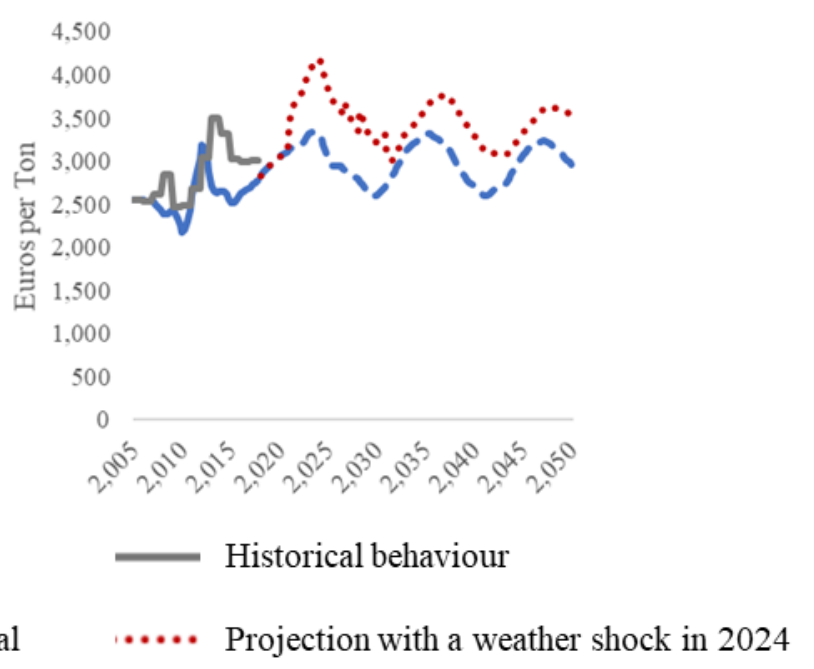

Figure 3 Beef production and beef price response to a) a moderate shock and b) an extreme shock on the weather conditions for three years.

The behaviour shown in Figures 4 illustrate the difference between adaptation and transformation. If the variation on the weather is moderate, the simulated results shown in Figure 4a suggests the system will underperform for a relatively short period of time but the system is eventually able to bounce back. This type of response is described in the resilience literature as 'adaptation' (Walker et al, 2004).

The mechanisms driving adaptation can be better understood by looking at the underlying structure of the system (Sieber et al, 2018; Biesbroek et al, 2014). Climate change effects reduce crops productivity increasing the production costs of the beef cattle industry. In the short term, the unbalance between crop supply and demand increases crops prices and encourages an increase on UAA (see Figure 4a). More UAA results on higher crop production what in turn reduces production costs for livestock farmers. The temporal reduction in the production costs gives the farmers an opportunity to recover after years receiving lower margins see Figures 4a.

Alternatively, if the weather variations are too intense and or occur often, the simulated results suggest that the system will move towards a new equilibrium state (Figure 4b). This type of response is known in the resilience literature as 'transformation' and the mechanisms driving this response in the system can also be understood by looking at the system structure. In these cases, the adjustments 


\section{Herrera and Kopainsky}

described above in price are not enough to balance the system because the equity needed during the periods of poor performance makes it economically unattractive to remain in the business (see for example Figure $4 b$ ). Because the burning of climate change is too big to bear with, farming systems are likely to respond by shrinking to more efficient sizes and could potentially disappear.

a) System response to an extreme shock

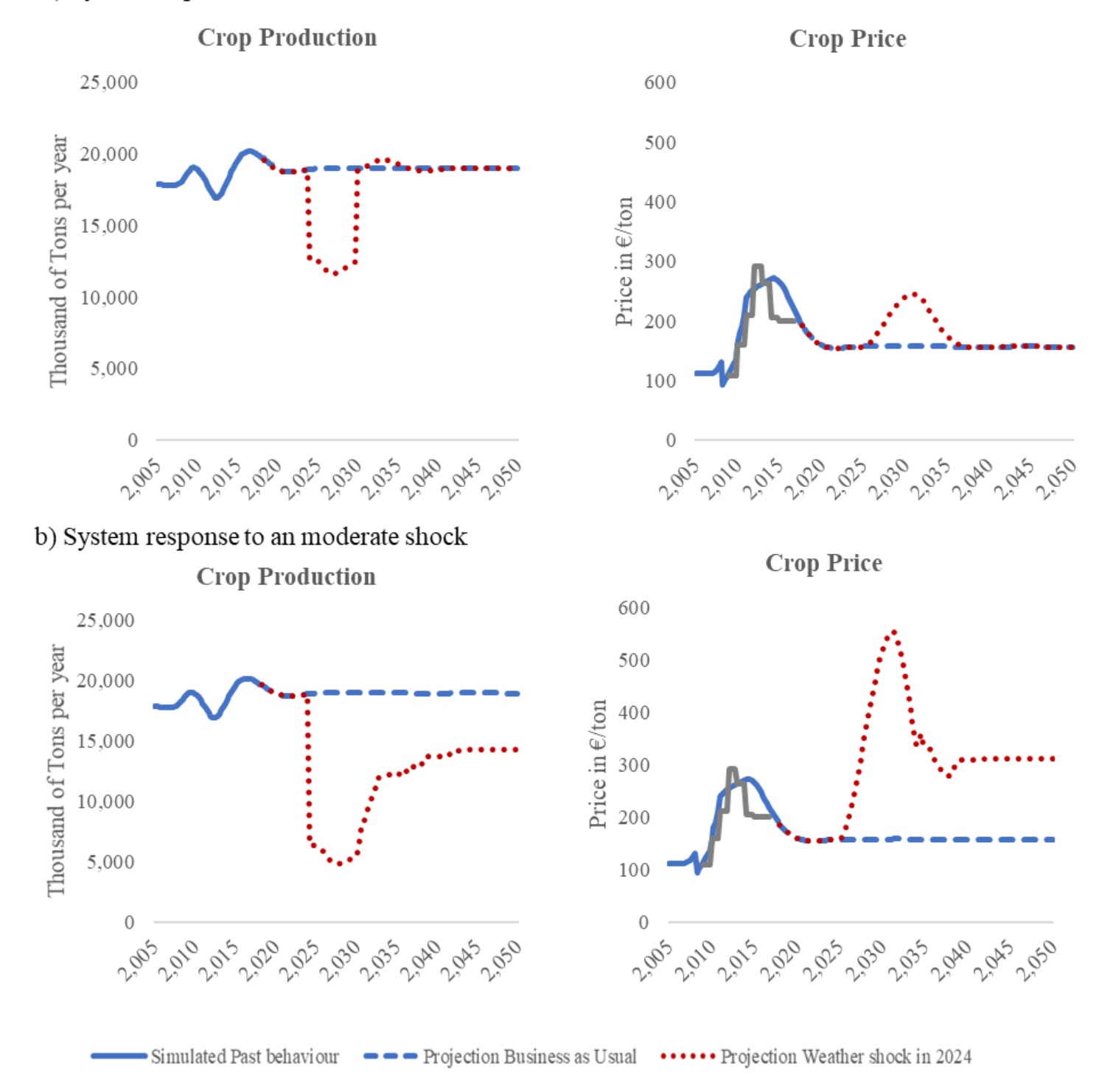

Figure 4 Crop system response to a a) moderate shock and b) extreme shock on the weather conditions in 2024

\subsection{Exploring trade-offs: Imports vs local production}

As described in Section 3, climate change has a direct effect on crops yields through water scarcity and the increase of pests and an indirect effect on the demand for crops through the reduction of forage available in the grasslands. Both reduction of yields and increase dependency on crops result on higher costs than otherwise for livestock producers, however, they have opposite effects for crop producers who seen a reduction in their throughput but an increase in their price. The long-term response of crop farmers is then governed by the elasticity of the markets and heavily influenced by market openness to foreign crops and logistic constraints.

Figure 5 shows the response of the crop production and the beef production to a shock in weather conditions when a) local crops cannot be easily substitute by foreign crops (e.g. because quotas or tariffs are in place) and b) local crops are easily replaced by foreign ones. As shown in the figure, openness to markets increases resilience of beef production but reduces resilience of crop production. 


\section{Herrera and Kopainsky}

Moreover, in the long-term, beef production becomes more dependent on foreign supplies potentially decreasing its resilience to market disturbances.

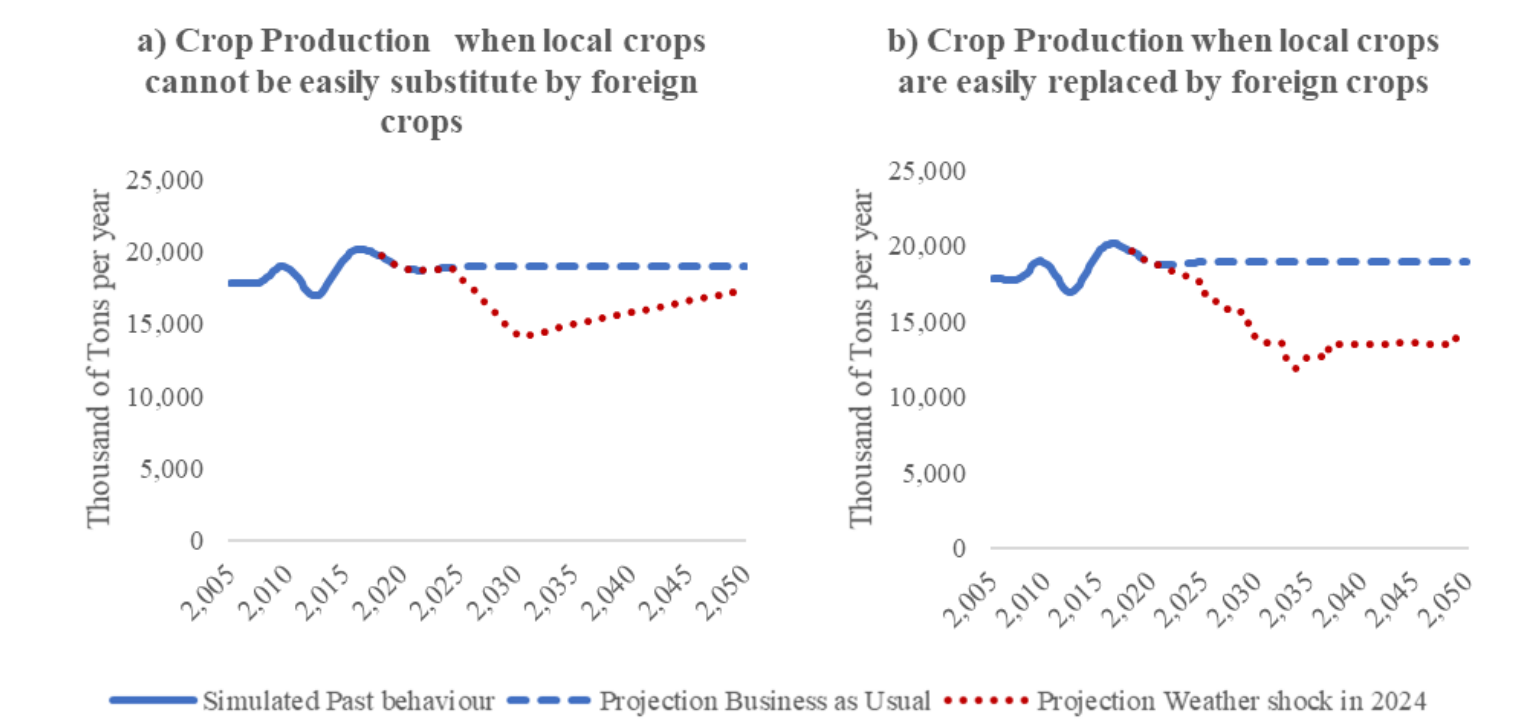

Figure 5 Crop system response to an increase on weather variability when a) local crops cannot be easily substitute by foreign crops and b) local crops are easily replaced by foreign ones

\section{CONCLUSIONS}

Fostering security of supplies, stability of price and financial viability of European farms in times of climate change is vital for the economic wellbeing of rural regions. Hence, although complex and challenging, resilience management of farming systems is a pressing task that needs to be undertaken. In this paper we make a case for supporting the resilience management process with small SD models that help policymakers to make sense of the problem at hand. The results in this paper show that are at least three clear benefits from taking this approach. First, small models allow us to aggregate complex systems into their main dynamics helps to understand what are the underlying mechanisms driving systems responses. The diagrams and simulation results presented in this paper illustrate how theoretical and empirical knowledge can be translated into mathematical tools that facilitate a discussion about resilience and its drivers.

Second, the simplicity and transparency of the models used also ease the analysis and discussion of potential points for intervention and strategies that can enhance resilience. Whereas the simulation results produced by the model are not meant to offer an accurate prediction of future developments, the analysis we presented shows how simulation results can be used to explore the complex mechanisms fostering resilience.

Third, having this kind of microworlds where we can experiment with different strategies might help stakeholders to understand some trade-offs between different types of resilience. As shown in this paper, looking at the simulation results and model structures makes evident some trade-offs between resilience to climate change and resilience to fluctuations in commodity markets. The results also highlight the presence of conflicting objectives between crop farming and livestock farming.

\section{REFERENCES}

Berkes F (2009). Evolution of co-management: role of knowledge generation, bridging organizations and social learning. Journal of environmental management 90(5): 1692-1702.

Biesbroek GR, Termeer CJ, Klostermann JE and Kabat P (2014). Rethinking barriers to adaptation: Mechanism-based explanation of impasses in the governance of an innovative adaptation measure. Global Environmental Change 26: 108-118. 


\section{Herrera and Kopainsky}

Biggs R, Schluter M, Biggs D, Bohensky EL, Burnsilver S, Cundill G, ... West, PC (2012). Toward Principles for Enhancing the Resilience of Ecosystem Services. Annual Review of Environmental Resources 37: 421-448.

Campbell BM, Vermeulen SJ, Aggarwal PK, Corner-Dolloff C, Girvetz E, Loboguerrero AM,... Wollenberg E (2016). Reducing risks to food security from climate change. Global Food Security 11: 34-43.

Carpenter SR, and MG Turner (Eds) (2000). Special issue on interactions of fast and slow variables in ecosystems 3(6): 495-595.

Carpenter SR, Brock WA (2008). Adaptive capacity and traps. Ecology and Society 13 (40).

Davidson DJ (2010). The applicability of the concept of resilience to social systems: some sources of optimism and nagging doubts. Society and Natural Resources 23(12): 1135-1149.

De Bruijn KM, Diermanse FLM and Beckers, JVL (2014). An advanced method for flood risk analysis in river deltas, applied to societal flood fatality risk in the Netherlands. Natural Hazards and Earth System Sciences 14(10): 2767-2781.

De Bruijn K, Buurman J, Mens M, Dahm R, Klijn F (2017). Resilience in practice: Five principles to enable societies to cope with extreme weather events. Environmental Science \& Policy 70: 2130.

Eakin HC and Wehbe MB (2009). Linking local vulnerability to system sustainability in a resilience framework: two cases from Latin America. Climatic change 93(3-4): 355-377.

Ericksen P (2008). What Is the Vulnerability of a Food System to Global Environmental Change? Ecology and Society 13(2): 18.

Fath BD, Dean C and Katzmair H (2015). Navigating the adaptive cycle: an approach to managing the resilience of social systems. Ecology and Society 20(2).

Folke C, Carpenter SR, Walker B, Scheffer M and Chapin T (2010). Resilience Thinking: Integrating Resilience, Adaptability and Transformability, Ecology and Society 15(4).

Herrera H (2017). From metaphor to practice: Operationalizing the analysis of resilience using system dynamics modelling. Systems Research and Behavioral Science 34(4): 444-462.

Holling C (1986). The resilience of terrestrial ecosystems: local surprise and global change. Pages 292-317 in W. C. Clark and R. E. Munn, editors. Sustainable development of the biosphere. Cambridge University Press, Cambridge, UK.

Holling CS, Gunderson LH (2002). Panarchy: Understanding transformations in human and natural systems.

Intergovernmental Panel on Climate Change (IPCC) (2013). Working Group I Contribution to the IPCC Fifth Assessment Report, Climate Change 2013: The Physical Science Basis.

Knickel K, Redman M, Darnhofer I, Ashkenazy A, Chebach TC, Šūmane S, ... and Strauss A (2018). Between aspirations and reality: Making farming, food systems and rural areas more resilient, sustainable and equitable. Journal of Rural Studies 59: 197-210.

Lien G, Hardaker JB and Flaten O (2007). Risk and economic sustainability of crop farming systems. Agricultural systems 94(2): 541-552.

Ludwig D, Jones D, Holling C (1978). Qualitative analysis of insect outbreak systems: the spruce budworm and forest. Journal of Animal Ecology 47:315-332

Meuwissen, M. P., Feindt, P. H., Spiegel, A., Termeer, C. J., Mathijs, E., de Mey, Y., ... \& Vigani, M. (2019). A framework to assess the resilience of farming systems. Agricultural Systems, 176, 102656.

Nettier B, Dobremez L, Lavorel S and Brunschwig G. (2017). Resilience as a framework for analyzing the adaptation of mountain summer pasture systems to climate change. Ecology and Society 22(4).

Saifi B and Drake L (2008). A coevolutionary model for promoting agricultural sustainability. Ecological Economics 65(1): 24-34.

Sieber IM, Biesbroek R and de Block D (2018). Mechanism-based explanations of impasses in the governance of ecosystem-based adaptation. Regional environmental change 18(8): 2379-2390.

Silanikove N and Koluman N (2015). Impact of climate change on the dairy industry in temperate zones: predications on the overall negative impact and on the positive role of dairy goats in adaptation to earth warming. Small Ruminant Research 123(1): 27-34. 


\section{Herrera and Kopainsky}

Schmidhuber J and Tubiello FN (2007). Global food security under climate change. Proceedings of the National Academy of Sciences of the United States of America 104(50): 19703-8.

Vermeulen SJ, Campbell, BM and Ingram J. (2012). Climate Change and Food Systems. Annual Review of Environmental Resources 37: 195-222.

Walker B, Carpenter S, Anderies J, Abel N, Cumming G, Janssen M ... and Pritchard R (2002). Resilience management in social-ecological systems: a working hypothesis for a participatory approach. Conservation ecology 6(1).

Walker B, Holling CS, Carpenter SR and Kinzig A (2004). Resilience, adaptability and transformability in social--ecological systems. Ecology and Society 9(2): 5.

Walker B, Carpenter S, Rockstrom J, Crépin AS and Peterson G (2012). Drivers," slow" variables," fast" variables, shocks, and resilience. Ecology and Society 17(3).

Wheeler T and Von Braun J (2013). Climate change impacts on global food security. Science 341(6145): 508-513.

\section{AUTHOR BIOGRAPHIES}

HUGO HERRERA received a MSc. from the European Master in System Dynamics in $2015 \mathrm{He}$ completed his PhD System Dynamics in the University of Bergen in 2018. Hugo is passionate about system dynamics analysis and modelling techniques and applies them in a variety of contexts. Hugo is affiliated to The University of Bergen and is currently part of the SUREFarm project.

BIRGIT KOPAINSKY is a lecturer at The University of Bergen, Norway. In her research, Birgit explores the role that system dynamics analysis and modelling techniques play in facilitating transformation processes in social-ecological systems, such as the transition towards sustainable agrifood systems on local, national and international levels. Birgit works both in Europe and in several sub-Saharan African countries and is currently part of the SUREFarm project. 